\title{
Tsafon
}

Revue d'études juives du Nord

$75 \mid 2018$

Exil des langues - Langues d'exil

\section{Mémorial de la Shoah : Voyage mémoriel à Thessalonique 15-19 mars 2018}

Danielle Delmaire

\section{(2) OpenEdition}

1 Journals

Édition électronique

URL : https://journals.openedition.org/tsafon/671

DOI : $10.4000 /$ tsafon. 671

ISSN : 2609-6420

Éditeur

Association Jean-Marie Delmaire

Édition imprimée

Date de publication : 1 juin 2018

Pagination : 174-176

ISSN : 1149-6630

\section{Référence électronique}

Danielle Delmaire, « Mémorial de la Shoah : Voyage mémoriel à Thessalonique 15-19 mars 2018 »,

Tsafon [En ligne], 75 | 2018, mis en ligne le 06 mai 2019, consulté le 24 juin 2021. URL : http:// journals.openedition.org/tsafon/671 ; DOI : https://doi.org/10.4000/tsafon.671

Tsafon. Revues d'études juives du Nord 


\section{Mémorial de la Shoah : Voyage mémoriel à Thessalonique 15-19 mars 2018}

par Danielle Delmaire

Le Mémorial de la Shoah (Paris) a organisé, du 15 au 19 mars 2018, un voyage mémoriel à Thessalonique la «Jérusalem des Balkans ». Nous étions un groupe d'une quarantaine de personnes, accompagné de Mathias Orjekh, coordinateur des voyages d'étude au Mémorial de la Shoah. Le but du voyage était de nous rendre sur les traces, nombreuses, du glorieux passé juif de la ville et de nous recueillir sur les lieux où la communauté juive a commencé de disparaître dans la Shoah. L'émotion était souvent présente lors de nos visites mais elle fut très prégnante lors de la marche commémorative du départ du premier convoi de déportation qui quitta Thessalonique le 15 mars 1943. La municipalité conduite par son maire, Yiannis Boutaris ${ }^{1}$, organise cette marche pour rappeler la persécution en l'encontre des Thessaloniciens juifs et exiger la mise hors la loi de tout acte antisémite et/ou raciste. Cette année, la marche commémorait le $75^{\mathrm{e}}$ anniversaire de ce premier convoi, suivi de dix-huit autres au départ de la ville. Comme les années précédentes, la marche partit de la place de la Liberté vers la gare. Des délégations de diverses communautés y participaient dont la délégation d'Israéliens originaires de Thessalonique.

Durant ces cinq journées, nous avons pu découvrir les demeures des plus riches familles juives qui sont encore debout ainsi que le marché couvert construit grâce à la famille Modiano, entre les deux guerres. Nous avons visité les deux seules synagogues de la ville. Nous avons bénéficié d'une visite du musée juif, guidée par Madame Hella Matalon, membre de la communauté juive et issue d'une ancienne famille. Nous avons pu aussi nous recueillir sur le monument rappelant l'emplacement de l'ancien cimetière juif, détruit, à partir de décembre 1942, à la demande de la municipalité et par des ouvriers municipaux (source : Mémorial de la Shoah). Il se trouve à l'université qui a été érigée sur les ruines du cimetière dont les débris ont servi à la reconstruction de plusieurs édifices de la ville, après la guerre. Nous avons encore profité des compétences de Léon Saltiel, historien, qui nous informa sur le passé juif de la ville grâce à un diaporama. Quelques-uns d'entre nous appartenaient à des familles juives de Thessalonique : ils ont pu parfois recueillir des souvenirs familiaux, peu connus voire inconnus d'eux.

Nous avons pu encore constater l'importance de l'usage du français dans la communauté juive actuelle, entretenu par l'Institut français qui possède une école française, de la maternelle au lycée, ouverte aux Français ainsi qu'à d'autres nationalités.

\section{Petite histoire de Thessalonique la juive}

La présence de juifs à Thessalonique est presqu'aussi ancienne que la ville elle-même. Celle-ci fut créée par Cassandre, général d'Alexandre le conquérant de l'Asie à la fin du $I^{\mathrm{e}}$ siècle avant notre ère. Or dès le premier siècle, la communauté juive était importante puisqu'elle fut visitée par un certain juif Shaul, dit Paul de Tarse, qui vint parler dans la synagogue (Actes des apôtres 17,1) et qui rédigea deux épîtres pour les juifs de Thessalonique. Par la suite, la communauté juive se développa ou diminua mais sa présence persista sous l'empire byzantin et, au XII ${ }^{\mathrm{e}}$ siècle, le voyageur juif Benjamin de Tudèle y dénombra environ 500 juifs. Les plus anciens habitants juifs étaient appelés

\footnotetext{
${ }^{1}$ Lire son discours lors de la pose de la première pierre du musée de l'Holocauste du 31 janvier 2018 dans notre rubrique « Édition ».
} 
Romaniotes. Au début de la domination ottomane, en 1430, la communauté était réduite mais elle s'agrandit considérablement avec l'arrivée de juifs expulsés de la péninsule ibérique à partir de 1492. Des familles riches ou pauvres s'installèrent et prirent part au développement commercial, artisanal puis industriel du port. À la fin du XIX ${ }^{\mathrm{e}}$ siècle, les habitants juifs représentaient environ $60 \%$ de la population totale. Deux incendies ravagèrent le quartier juif en bordure du port, l'un en 1890 et l'autre, très meurtrier, en 1917. En conséquence, des familles quittèrent la ville et un certain nombre se dirigea vers la Palestine mandataire, notamment vers un autre port, Haïfa.

Dans cette « Jérusalem des Balkans » s'épanouirent une culture et une spiritualité juives très riches. L'apport des juifs de la péninsule ibérique fut considérable, notamment la langue judéo-espagnole dans laquelle furent composées des œuvres poétiques. De nombreuses écoles talmudiques ouvrirent et les synagogues ne désemplissaient pas; la plus importante de la soixantaine de synagogues existantes à Thessalonique au début du $\mathrm{XX}^{\mathrm{e}}$ siècle était la synagogue Talmud Torah ha Gadol, fondée en 1520. L'Alliance israélite universelle implanta un important établissement scolaire, contribuant à répandre la langue française pratiquée par de nombreux juifs thessaloniciens.

Cette considérable communauté juive attira Shabbataï Zvi qui y fit des adeptes : les dönmes ou juifs convertis à l'islam qui constituèrent une communauté à part dans la Thessalonique ottomane, la plus célèbre de tout l'empire. Quelques-uns de ses membres occupèrent des postes importants dans l'administration de la ville et dans les activités économiques, à la fin du $\mathrm{XIX}^{\mathrm{e}}$ siècle et au début du $\mathrm{XX}^{\mathrm{e}}$.

Après la Grande Guerre, suite aux échanges de populations entre la Grèce et la Turquie, conséquence du traité de Lausanne (1923) dont le but était d'homogénéiser les populations sur le plan religieux, les musulmans et les dönmes furent déplacés vers la Turquie tandis que les chrétiens grecs devaient quitter la Turquie. La communauté juive fut très peu touchée par ces échanges de populations, en revanche elle eut à souffrir de l'antisémitisme des nationalistes grecs. Cette menace et des difficultés économiques expliquent une émigration vers les USA, l'Europe occidentale et la Palestine.

À la fin de l'année 1940, l'Italie étendit ses visées hégémoniques à la Grèce qui résista quelques mois mais, en avril 1941, Thessalonique fut occupée par les Allemands. Le 11 juillet 1942, ces derniers organisèrent le tristement célèbre shabbat noir : 8500 hommes, âgés de 18 à 45 ans, durent se rassembler sur la place de la Liberté (la mal nommée) pour des exercices physiques inutiles et humiliants, sous un soleil d'été écrasant, provoquant des malaises chez certains. Puis les juifs furent obligés de se regrouper dans deux ghettos dont le ghetto Hirsch, peu éloigné de la gare. Enfin, en mars 1943 commença leur déportation vers Auschwitz. Les premiers départs furent facilités par la propagande nazie qui faisait croire que les juifs déportés allaient travailler à Cracovie. Le rôle du rabbin Zvi Koretz, un Autrichien germanophone nommé à Thessalonique peu avant la guerre, reste controversé car il ne s'est pas opposé aux exigences des nazis. En cinq mois, entre le 15 mars et le 18 août 1943, 48533 juifs de Thessalonique furent déportés à Auschwitz, en 19 convois (source : Mémorial de la Shoah). L'écrasante majorité ne revint pas. Jacques Stroumsa, qui fit partie du convoi 16 du 8 mai 1943, avec son épouse enceinte de huit mois, toute sa famille et sa bellefamille, a raconté son calvaire : il échappa à la mort grâce à ses talents de violoniste et d'ingénieur, mais sa jeune femme et sa famille furent exterminées (Jacques Stroumsa, Tu choisiras la vie, violoniste à Auschwitz, Paris, Cerf, 1998). Quelques juifs bénéficièrent d'aide pour se cacher mais ils étaient trop nombreux pour se dissimuler dans la ville. D’autres enfin parvinrent à rejoindre les rangs de la Résistance dans des maquis.

$\mathrm{Au}$ lendemain de la guerre, la Grèce fut en proie à une guerre civile qui empêcha les rares rescapés de reconstituer rapidement une communauté. En outre, ils eurent la douleur de constater que leurs maisons étaient investies par des occupants qui refusaient 
de les quitter, ou bien que des objets, qu'ils croyaient perdus, se trouvaient entre les mains de Thessaloniciens.

Actuellement, la communauté compte environ 1000 personnes et deux synagogues mais la ville conserve les traces de son glorieux passé juif.

Marche mémorielle du premier convoi de déportation des juifs de Thessalonique (photos D. Delmaire)

En tête de la marche : Poté Xana, Plus Jamais

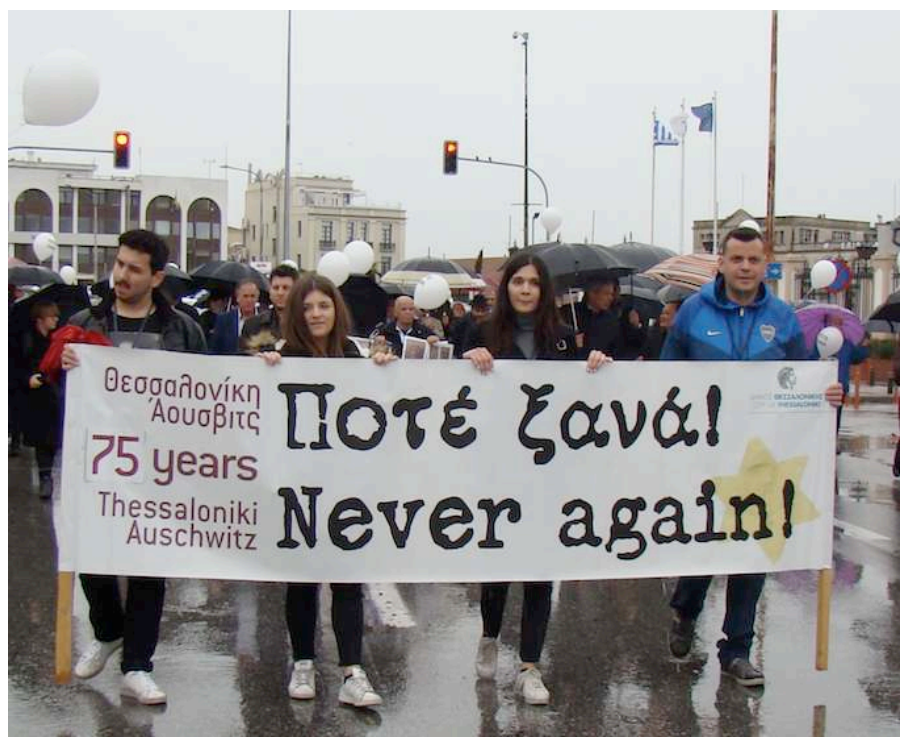

À la vieille gare de Thessalonique, des participants à la marche accrochent des ballons blancs à des wagons (ceux-ci ne datent pas de la déportation)

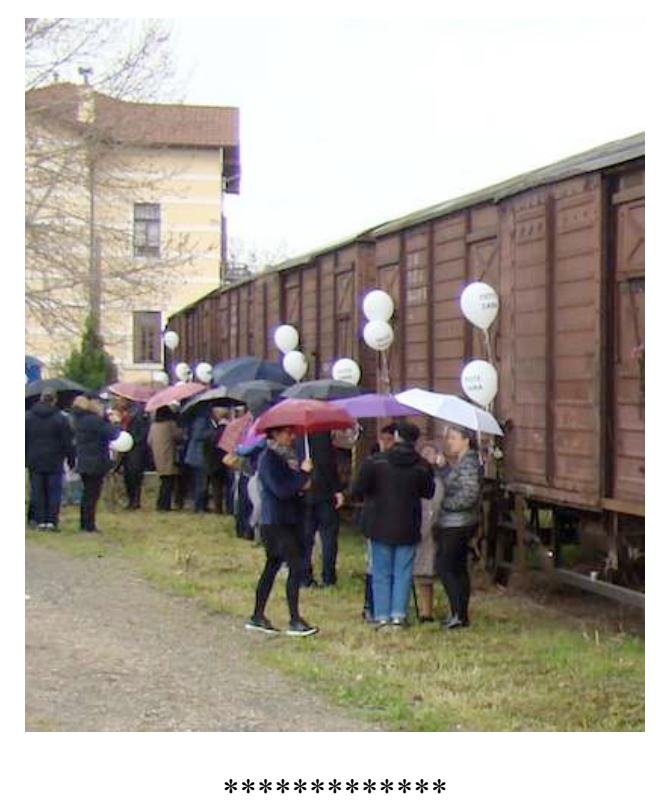

